\title{
Del diario a la epifanía: una lectura posautónoma de La novela luminosa de Mario Levrero
}

\author{
From dairy to epiphany: a post-autonomous reading \\ of Mario Levrero's La novela luminosa
}

\author{
Diego GonzÁlez Velazco \\ ORCID: 0000-0002-7550-1016 \\ Universidad Iberoamericana, Ciudad de México, México. \\ diegoglezvel93@outlook.com
}

Resumen:

La obra de Mario Levrero ha generado varios debates por su construcción narrativa, el uso de un sinsentido que recuerda a Lewis Carroll en ciertos casos y, en el caso de La novela luminosa, la escritura de un trabajo reflexivo en forma de diario íntimo. Este trabajo explica una lectura crítica de La novela luminosa de Mario Levrero, desde una concepción que va más allá de la autonomía literaria, es decir, la concepción de posautonomía, propuesta de Josefina Ludmer; para hablar de la aparición de nuevas escrituras y formas de leer críticas que se construyen a partir de una retórica del testimonio, pensada desde la teórica Beatriz Sarlo. Se configuran así territorialidades y temporalidades del presente, donde el pasado se rememora y el futuro se ha perdido. De igual manera, se indaga en la construcción de una neoepifanía, concepto de Óscar Brando, por parte del autor-narrador sobre la muerte, que se da a partir de las nuevas concepciones de temporalidad y preceptos de la posmodernidad.

Palabras clave:

Mario Levrero, posautonomía, narrativa testimonial, posmodernidad, temporalidad del presente. 


\section{Abstract:}

The work of Mario Levrero has generated multiple debates for its narrative construction, the use of nonsense that reminds the one by Lewis Carroll and, in the case of La novela luminosa, the writing of a reflexive work in the form of an intimate diary. This work explains a critic reading of Levrero's La novela luminosa, from a conception that goes beyond the literary autonomy, that is to say, the post-autonomy conception, a concept by Josefina Ludmer; to speak about the emergence of new critic writings and ways of reading that are built on a rethoric of testimony, thought from the researcher Beatriz Sarlo. Thus configuring territorialities and temporalities of the present, where the past is rememorated in the now, and the conception of a future has been lost. Similarly, this work explores the construction of a neo-epiphany, a concept by Óscar Brando, about the conception of death by the author-narrator, given by the new conceptions of temporality and the precepts of postmodernity.

Key words:

Mario Levrero, post-autonomy, testimonial narrative, postmodernity, temporality of the present.

DOI: https://doi.org/10.36798/critlit.vi22.366

Recibido: 27 de octubre de 2020

Aceptado: 21 de enero de 2021

Alcanzar la luminosidad parecía una tarea imposible para Mario Levrero (1940-2004), su búsqueda por exorcizar su temor a la muerte lo llevó por un trabajo reflexivo en torno a diversos temas, bajo la narración de un diario íntimo; donde el ocio y el aburrimiento tomaron posesión de su vida y le imposibilitaron la tarea de poder escribir $\mathrm{La}$ novela luminosa. Por su parte, esa tarea de escritura logró configurarse para crear una sensación de presente inmediato y la capacidad de difuminar la línea entre la realidad y la ficción, ambas características de "las literaturas posautónomas", término utilizado por Josefina Ludmer para referirse a una concepción de la literatura más allá de lo 
autónomo. Ahora bien, la construcción de momentos reflexivos en el instante de la escritura, provoca la teorización sobre la muerte para construir una neoepifanía, donde se logra apreciar una concepción sobre lo que sucede durante y después de la muerte del individuo y de la muerte simbólica de aquel espíritu, que pone en marcha el proyecto de escribir una novela donde se represente de forma orgánica una de sus obsesiones: la muerte. En este trabajo se busca demostrar que en La novela luminosa ocurre la construcción de la concepción de posautonomía, propuesta de Josefina Ludmer, a partir de una retórica del testimonio, pensada desde Beatriz Sarlo. De igual manera, se mostrará la configuración de una neoepifanía, concepto de Óscar Brando, que se da a partir del instante de la escritura.

El análisis del texto planteado en este trabajo es a partir de la lectura minuciosa de tres discursos recurrentes dentro del texto trabajado de Levrero: el de la cotidianidad, el de los sueños y el de la observación. El primero se centra en la narración de lo nimio, donde se construyen instantes reflexivos. En esta parte se demostrará que esos momentos de devaneo se construyen a partir de la inmediatez de la escritura para abordar temas como: el erotismo, la pornografía, el ocio y, el interés de este trabajo, la muerte. De igual manera, se planteará la existencia de una realidadficción, término de Ludmer, a partir de la existencia de un autor-narrador y el uso de una retórica que es construida a partir de una memoria a corto plazo.

Por su parte, los sueños toman un rumbo diferente como argumento. En este caso, el tema de la muerte es representado a partir de elementos simbólicos, su significado a partir del tarot y las precogniciones. De igual manera, en este discurso se planteará la idea de parapsicología, vista desde la concepción levreriana, que aparece en la novela. Por último, el discurso de la observación será analizado para dar a conocer la construcción de una neoepifanía, que se da a partir de una escritura reflexiva del instante. Así se construye una idea sobre la muerte de manera íntima y, al mismo tiempo, se plantea qué sucede después de la muerte de un individuo y de la muerte del espíritu que dio origen al impulso de escribir una novela luminosa; esto último visto como una simbología. 
El analizar La novela luminosa desde una perspectiva contemporánea -Josefina Ludmer, Beatriz Sarlo, Óscar Brando, entre otros - ayuda a dar un nuevo lugar a un escritor, malentendido diversas veces. Mario Levrero se ha mantenido un poco en las sombras de la crítica literaria en el pasado, pero actualmente ha sido retomado por su íntima ideología propia, que él prefiere plasmar en historias donde se configura una gran complejidad narrativa. De igual manera, se busca entablar un diálogo entre los conceptos contemporáneos mencionados, para señalar la existencia de una crítica hacia el estatuto literario establecido en el siglo XX.

\section{Nuevas perspectivas de la literatura}

La trilogía luminosa ${ }^{1}$, considerada así por Helena Corbellini, ha dado origen a otro gran campo de investigación, debido a que las tres obras que la integran fueron escritas a manera de diario íntimo. En ellas aparecen reflexiones sobre las obsesiones cotidianas del autor, en especial, "el significado de ser escritor ... . escribir es una necesidad de su alma que derrama, a la vez, angustia y alivio" (Corbellini 251). Esa angustia está presente cuando el autor está en busca de la luminosidad ${ }^{2}$ que parece inalcanzable ante sus ojos, pero existen dos motivaciones que lo animan a seguir: "la primera de las motivaciones consiste en responder a una imagen recurrente: una novela será escrita ... La segunda motivación es la de obedecer al deseo de narrar ciertas experiencias "luminosas"' (Laddaga 225).

${ }^{1}$ Diario de un Canalla (1992), El discurso vacio (1994) y La novela luminosa (2005).

2 Mario Levrero explica esa búsqueda de luminosidad en el "Prefacio Histórico a La novela luminosa": "El impulso inicial fue dado por una conversación dada con un amigo. Yo habría narrado a este amigo una experiencia personal que para mí había sido de gran trascendencia ... De acuerdo con mi teoría, ciertas experiencias extraordinarias no pueden ser narradas sin que se desnaturalicen; es imposible llevarlas al papel" (La novela 11). En pocas palabras, la luminosidad para el autor uruguayo, es el poder exorcizar su miedo a la muerte y al dolor a partir de la escritura. 
Pensar este texto reflexivo y testimonial desde la autonomía del arte, es una posibilidad, aunque no es el propósito de este estudio. La autonomía debe ser concebida como "lo que encontramos en las auténticas obras de literatura moderna. Ellas se objetivizan para sumergirse completamente de manera monadológica en las leyes de sus propias formas, leyes que están estéticamente enraizadas en su propio contexto social" (Adorno 166; traducción mía). ${ }^{3}$ Es decir, son obras, literarias para fines de este trabajo, que se valen por sus propias leyes y tienen vida propia, al igual que "señalaban la distancia entre realidad y ficción” (Brando 239). Desde el punto de vista de la crítica argentina Josefina Ludmer, la autonomía literaria ha llegado a su fin, por lo tanto, ella propone un concepto que va más allá de lo autónomo, es decir, el de la posautonomía literaria. Este propone que existen nuevas formas de escritura que están generando una resistencia a los estatutos modernos de la literatura, construyen presente a partir de una nueva concepción temporal del ahora, donde el pasado es rememorado y la promesa de un futuro se ha perdido. Son textos que rebasan las fronteras propuestas por la autonomía.

Ludmer comienza a construir este concepto cuando dice que ha llegado "el fin de una historia de la literatura y el arte" (Aqui 91), y agrega dos postulados de la ideología cultural de la posmodernidad, dados por Frederick Jameson, donde "el primero es que todo lo cultural (y literario) es económico y todo lo económico es cultural (y literario). Y el segundo postulado ... sería que la realidad (si se la piensa desde los medios, que la construirían constantemente) es ficción y que la ficción es realidad" (151). ${ }^{4}$ Así comenzó un debate en el cono sur de Sudamérica "cuyo objeto no era (no es) sólo el

3 'This is exactly what we find in authentic works of modern literature. They objectify themselves by immersing themselves totally, monadologically, in the laws of their own forms, laws which are aesthetically rooted in their own social content" (Adorno 166).

${ }^{4}$ Los paréntesis fueron agregados por Josefina Ludmer para hacer énfasis en lo literario. 
paso de un sistema literario a otro sino también, y sobre todo, la puesta en cuestión, y hasta la transformación, del estatuto mismo de la literatura hoy, de su concepto y de los valores a él asociados" (Contreras 1). Con esta última cita se da a entender que estos nuevos modos de escritura reconfiguran y resisten el estatuto autónomo de la literatura, generando así, nuevas perspectivas de lectura.

De igual manera, las escrituras posautónomas "reformulan la categoría de la realidad: no se las puede leer como mero realismo, en relaciones o referencias verosimilizantes. Toman la forma del testimonio, la autobiografía, el reportaje periodístico, la crónica, el diario íntimo y hasta la etnografía" (Ludmer, Aqui 151). Crean así una concepción cultural donde existe la construcción de una temporalidad y territorialidad del presente, al igual que la desaparición de la línea que separa a la realidad de la ficción. ${ }^{5}$

Por su parte, Beatriz Sarlo indagó en el mismo tema a partir del análisis de las escrituras testimoniales o, como dice en su libro Tiempo pasado, "escrituras de la memoria". La teórica propone que estas nuevas formas de escritura vuelven a "la literatura high fidelity etnográfica" (“¿Pornografía o fashion?” 16), es decir, "se instalan localmente y en una realidad cotidiana para fabricar presente y ese es precisamente su sentido" (Ludmer, Aqui 149). Al mismo tiempo, critica este tipo de literatura "al ser poco correcta y previsible, representando lo que legitimó antes la televisión, pierde toda capacidad de escandalizar. Y probablemente toda capacidad de divertir" (Sarlo, “¿Pornografía o fashion?” 16), por lo tanto, y dentro de la misma propuesta de Sarlo, estas nuevas formas de escritura ya no pueden ser leídas como literatura.

A su vez, Sarlo logra trabajar la retórica de lo testimonial para continuar su indagación en torno a la polémica que lo posautóno-

${ }^{5}$ Josefina Ludmer, en Aqui América Latina. Una especulación, considera esto como una realidadficción a partir de la concepción de un Tiempo Cero, el cual "reorganiza el mundo y la sociedad y produce todo tipo de fusiones y divisiones... . fusiona los opuestos y hace porosas las fronteras entre el tiempo privado y público, entre presente y futuro, y también entre ficción y realidad" (Ludmer, Aquí19). 
mo ha causado. La crítica propone que "no hay testimonio sin experiencia, pero tampoco hay experiencia sin narración” (Tiempo 29), es decir, el testimonio se construye a partir de una experiencia que debe ser narrada para poder tener el carácter de lo testimonial. De igual manera, existe un elemento muy importante: el de la memoria; una que hace posible "una reconstrucción del pasado, se abren vías de la subjetividad rememorante y de una historia sensibilizada a ella pero que se distingue conceptual y metodológicamente de sus narraciones" (92). Esta subjetividad problematiza las escrituras que se plantean en narrar una verdad, entonces, "si ya no es posible sostener una Verdad, ${ }^{6}$ florecen en cambio unas verdades subjetivas que aseguran saber aquello que ... se consideraba oculto por la ideología o sumergido en procesos poco accesibles a la introspección simple" (51). Esto provoca que lo leído genere desconfianza en el lector, al dudar de la veracidad de los hechos. La memoria requiere también del uso de la imaginación y es por eso que contiene una parte ficcional. Otro teórico que toca la importancia de la imaginación en este tipo de escrituras es Alberto Giordano, cuando menciona la concepción de escribir en Mario Levrero: "no se escribe a partir de la invención sino del recuerdo de visiones espirituales" (243); a lo que se refiere es que uno no inventa, sino que en el arte de lo confesional se escribe a partir del recuerdo y la imaginación plasmada en el mismo.

Por su parte, Josefina Ludmer considera la memoria para sustentar el concepto de literaturas posautónomas. La teórica propone que "la memoria actual sería una respuesta a la caída del futuro y la necesidad de una doble temporalidad para construir un presente siempre dislocado y duplicado" (Aqui 58). En este caso

${ }^{6}$ El uso de la mayúscula es para hablar del concepto de Verdad Absoluta, entendida desde la historia como aquello construido a partir de "las distintas visiones que los historiadores ofrecen de un solo y único acontecimiento, según pertenezcan a épocas o generaciones diferentes, o, si son contemporáneos, según los distintos sistemas de valores en que se fundan y que son la expresión de los intereses de las clases opuestas, de concepciones del mundo divergentes..." (Schaff 74). 
debe pensarse que ya no hay un futuro sino un ahora, el pasado se vuelve parte del presente al ser recordado, por lo tanto, la concepción cultural del tiempo está colocada en la construcción de presente. Ahora bien, dentro de esta perspectiva de la memoria, Ludmer logra acordar con Sarlo la construcción de una realidadficción ${ }^{7}$ dentro de las escrituras a partir de la memoria y, al mismo tiempo, la generación de esa concepción temporal característica de la época posmoderna.

Rafael Arce habla de la existencia de un problema en torno al tema cuando menciona que "las literaturas posautónomas convivirán con otras que siguen portando marcas de autonomía... Sólo que las discusiones que ha suscitado Ludmer con esa especie de manifiesto crítico prueban de algún modo que no se trata de la convivencia pacífica de modos de escritura, sino de la coexistencia conflictiva de los modos de leer"' (Arce 17). Por su parte, Sandra Contreras tiene una perspectiva similar cuando dice que las literaturas posautónomas son "una salida para la lectura crítica" (7). Ambos críticos logran dar a conocer la importancia de esa convivencia con la lectura, pero deben considerar que el conflicto entre ambas concepciones críticas — la autonomía y la posautonomía — se da a partir de que las nuevas perspectivas están generando que estas nuevas escrituras critiquen y se resistan al estatuto de autonomía literaria.

Ludmer tiene una propuesta para poder superar esta rivalidad entre ambas concepciones cuando piensa en el monstruo ${ }^{8}$ Borges,

${ }^{7} \mathrm{La}$ concepción de realidadficción es una propuesta de Josefina Ludmer, donde menciona: "con la memoria estoy en la realidadficción no sólo porque en la memoria la realidad toma la forma de ficción, sino porque la memoria tiene la misma estructura temporal y subjetiva en la realidad y las ficciones" (Aqui 61); es decir, la memoria está inserta en un presente tanto en la realidad como en la ficción. En el caso de Beatriz Sarlo, la imaginación es la parte ficcional de la memoria. Tanto el recuerdo (lo real) como lo imaginado (lo ficcional) conviven en un mismo momento, por lo tanto, la memoria es una forma de realidadficción.

${ }^{8}$ Josefina Ludmer en su texto “¿Cómo salir de Borges?”, recopilado en el libro Jorge Luis Borges. Intervenciones sobre pensamiento y literatura, propone el adjetivo "monstruo" para definir al autor argentino, por la magnitud y universalidad de su 
desde donde posiciona su concepción de autonomía: "Desde dónde leer a Borges ... podría ser la pregunta que nos hace ver la superposición y la variabilidad de esas posiciones, que son subjetivas, culturales y sociales, y a la vez históricas, literarias e institucionales" (Jorge 289). Cómo dejar atrás a un escritor de la magnitud de Borges es la mayor preocupación de Ludmer, su respuesta es "disolverlo en las tradiciones para leerlo críticamente. Sacarlo del presente, leerlo desde adentro y desde el pasado y el futuro" (300). Volver a Borges una tradición ayudaría a generar nuevas perspectivas de lectura, en este caso, las de la posautonomía.

Desde la perspectiva de Óscar Brando, lo posautónomo debe continuar su camino para comenzar a pensar en nuevas posibilidades de análisis para las nuevas formas de escritura; así es como propone la configuración de neoepifanías. Primero que nada, este concepto se construye del prefijo neo ('nuevo') y de la palabra epifanía que, para fines de este trabajo, viene de la concepción de temporalidad que propone Walter Benjamin al ejemplificar la famosa pintura de Klee titulada "Angelus Novus":

Se ve un ángel al parecer en el momento de alejarse de algo sobre lo que clava la mirada ... Su cara está vuelta hacia el pasado. En lo que para nosotros aparece como una cadena de acontecimientos, él ve una catástrofe única . . . Esta tempestad lo arrastra irresistiblemente hacia el futuro, al cual vuelve las espaldas, mientras el cúmulo de ruinas sube ante él hacia el cielo. Tal tempestad es lo que llamamos progreso. (Benja$\min 40-41$ )

La concepción de historia de Benjamin vuelve a la epifanía en una concepción moderna del tiempo, donde la perspectiva cultural voltea a ver al pasado posicionándose desde el presente y es arrastrada hacia un futuro prometedor a partir de la concepción del progreso. Un gran ejemplo de epifanía en la literatura está en Ulises de James

obra, al igual que el peso que esta tiene sobre la literatura. 
Joyce, donde aparece una "repentina manifestación espiritual traducida por la vulgaridad de la palabra o el gesto. Esta revelación insignificante era pretextual, exigía una reelaboración para obtener una significación completa y compleja" (Brando 243). En pocas palabras, la cita anterior refiere a que la epifanía aparece antes de la escritura, debe ser narrada para poder aclarar lo que hay en la mente y a su vez, llegar a una comprensión casi total de esta.

Ahora bien, "las neoepifanías no se reelaborarían, sino que serían integradas al texto, siempre y cuando su trivialidad contuviese, como utopía cifrada, una posible revelación" (Brando 243). Brando, al proponer este nuevo concepto, establece que la luminosidad es una revelación que no genera texto, ya que esta debe ser generada a partir de la escritura; es decir, la neoepifanía aparece en el instante de la escritura misma. La concepción cultural del tiempo en este caso es diferente y se conecta con la propuesta de Josefina Ludmer cuando habla de una temporalidad donde solo se construye presente.

¿Dónde entra La novela luminosa de Mario Levrero en este esquema? La respuesta es la siguiente: la búsqueda de la luminosidad en su diario íntimo ha generado que se conciba una escritura que genera la construcción de una neoepifanía sobre la muerte a partir del uso de una retórica testimonial o de la memoria. Esto genera la creación de una realidadficción a partir de instantes que configuran presente, tanto temporal como territorial, desde un pasado inmediato.

\section{Crónica de una imposibilidad}

Mario Levrero, a partir de un desdoblamiento autorial, donde toma el rol de autor-narrador," relata, en el "Prefacio histórico a la novela luminosa”, cómo empezó a escribir La novela luminosa antes de que

${ }^{9}$ Se utilizará en este trabajo la concepción de autor-narrador, ya que la primera parte ancla al concepto con la realidad (autor) y la segunda con la ficción (narrador); con esto se propone la creación de lo que propone Josefina Ludmer como realidadficción. 
fuera operado de la vesícula en 1984. Aquí se presentaron sus dos mayores temores existenciales, es decir, el dolor y la muerte; así fue como el autor uruguayo trabajó contra reloj para dejar terminada esta novela que proponía alcanzar una luminosidad que era "el intento de exorcizar el miedo a la muerte" (Levrero, La novela 14). De ahí aparecieron los primeros cinco capítulos de la novela que fueron dejados a un lado al no poder representar aquella luminosidad, ya que Levrero tenía una teoría, como se mencionó anteriormente, en la que proponía que "ciertas experiencias extraordinarias no pueden ser narradas sin que se desnaturalicen; es imposible llevarlas al papel" (11), en otras palabras, sentía la imposibilidad de poder alcanzar un texto que representara de manera fiel una imagen obsesiva que estaba en su mente.

El volver a querer escribir este proyecto ocurrió cuando la John Simon Guggenheim Foundation otorgó una beca a Levrero. El dinero no logró que terminara aquel trabajo buscado, pero provocó la aparición de un extenso prólogo titulado "Diario de la beca", donde narra un año de ocio, observación y la imposibilidad de poder escribir una novela, pero al mismo tiempo configura momentos reflexivos que llevan a este texto más allá de una simple representación de lo nimio. De igual manera, da pie a la aparición del capítulo "Primera Comunión" y a la revisión y corrección de los cinco capítulos escritos con anterioridad.

El cierre de La novela luminosa se da a partir de un "Epílogo del diario", donde se tratan de cerrar las historias planteadas en el prólogo, pero estas terminan por quedar abiertas al volver a narrar desde el instante de la observación. La novela, que desde el prefacio hasta el epílogo fue escrita por Mario Levrero, contiene una estructura que problematiza el género literario al que pertenece, ya que puede ser considerado como novela, diario íntimo o texto filosófico por las reflexiones en las que abunda el autor. Por su parte, el juego de un desdoblamiento autorial pone en duda la misma narración de los hechos. Lo anterior es un claro ejemplo de resistencia a los estatutos impuestos por la concepción literaria vista desde la autonomía.

Ahora bien, el diario íntimo de Levrero presenta tres discursos —el de la cotidianidad, el de los sueños y el de la observación- 
que logran reflexionar sobre varios temas que giran en torno el día a día del autor-narrador, pero el tema que más resalta por su sutileza es el de la muerte. El reflexionar sobre este tema a partir de la escritura constante crea la construcción de una neoepifanía que trata de explicar lo que sucede después de morir desde el ámbito sentimental, el corporal y el trascendental.

\section{Narrando lo nimio}

La narración de lo cotidiano en la novela de Levrero es la línea base de la historia, lo que da así una rutina casi diaria de sus deberes como humano, escritor y ciudadano montevideano. Dentro de tanta aridez argumentativa, existen ciertos pasajes que terminan por profundizar en instantes donde el devaneo lleva a una vaga reflexión acerca de lo que observa, siente y percibe parapsicológicamente del mundo. Estos instantes, colocados en un punto medio entre el recuerdo y las expectativas del futuro, serán referidos en este texto como intergumentos. ${ }^{10}$ Por su parte, el autor-narrador, dentro de todo este relato donde predominan el ocio, la pornografía y las mujeres; solo tiene una imagen constante presente: el retorno a sí mismo para poder realizar el proyecto de una novela luminosa.

Para el autor-narrador, el ocio "es una disposición del alma, algo que acompaña cualquier tipo de actividad: no es la contemplación del vacío mismo; es, cómo decirlo, una manera de estar" (107). A lo que se refiere es que, para generar un estado de ocio correcto, es necesario tomar la actividad como lo más importante del día. A su vez, el autor-narrador propone el ocio como una vía para lograr escribir cuando menciona que el ocio es: "la cosa que esté haciendo me deje libre la mente, no la comprometa, o no la comprometa más

${ }^{10} \mathrm{El}$ intergumento debe ser entendido como un argumento que está posicionado entre el argumento de lo evidente, es decir: el ocio, lo cotidiano y lo nimio; y el argumento de la intimidad del autor-narrador: la obsesión, los sueños y el aburrimiento. 
que para la contemplación de la cosa que estoy haciendo" (107), para así poder alcanzar aquel retorno a su yo de 1984, aquella época donde comenzó la redacción de La novela luminosa.

Lo paradójico en este caso es la manera en que ese ocio es empleado, ya que se convierte en el factor que domina aquella imposibilidad por la escritura:

Encontré un libro de Gardner en el puesto vecino, y mi lista impresa desde la computadora me decía que faltaba en la colección, y mi memoria decía que no faltaba. Lo compré de todos modos. Llego a casa, y ahí estaba en el estante. Pero la base de datos tenía razón: al libro de mi biblioteca le faltaban hojas ... Debo anotar el sueño de hoy, el del "abismo". Ahora no tengo tiempo. (250-51)

En el final del fragmento anterior aparece una constante en las entradas del diario íntimo, ya que siempre hay interrupciones que dejan historias inconclusas, unas que pueden ser retomadas, o no, en la posterioridad del texto; son causa del ocio en forma de juegos de computadora, la búsqueda de imágenes eróticas de jovencitas japonesas, las visitas constantes que llegan a su departamento e incluso la lectura de novelas policiales.

Por su parte, la agorafobia del autor-narrador es la razón que lo mantiene encerrado la mayor parte del tiempo. Lo único que lo puede hacer aventurarse en las calles del Montevideo del 2000, son las múltiples mujeres y ex amantes que lo visitan, y de quienes omite sus nombres. El caso de Chl es el que tiene más peso en la historia al ser la mujer de la que sigue enamorado el autor-narrador:

Siento celos, tal vez injustificados ... porque aunque haya otro hombre, yo ya no soy la pareja de Chl, y tiene derecho, etcétera.... Pero esto tiene mucha relación con la historia que venía contando, de modo que aquí mismo dejo de escribir. (128)

Otra vez la imposibilidad de escribir aparece, en este caso a través de un derrumbe emocional que lo lleva a envolverse en alguno de los juegos de la computadora. La figura de Chl en el texto es consi- 
derada como una diosa, pero al mismo tiempo es la representación y el verdadero recordatorio de un acto sexual que nunca llegará. La imaginación erótica del autor-narrador no aparece en este caso. Él venera a Chl y la respeta hasta cierto punto. La carga erótica aparece en el momento que se cruza con una joven en el supermercado, el devaneo lo lleva a crear imágenes de gran peso: "Me fui dando cuenta que mi deseo era violento, y deseo más de violencia que de sexo ... No me imaginaba seduciéndola, sino forzándola. Domesticándola como un animal" (303). Aquí el placer de un deseo reprimido se desborda para comenzar ese retorno a un pasado perdido, al que nunca se podrá regresar.

Ahora bien, existe una retórica del testimonio que se empeña en generar una sensación de veracidad en torno a lo narrado. Para Beatriz Sarlo el testimonio es "el recurso más importante para la reconstrucción del pasado; discute la primera persona como forma privilegiada frente a discursos de los que la primera persona está presente o desplazada. La confianza en la inmediatez de la voz y del cuerpo favorece el testimonio" (Tiempo 23). En el caso de La novela luminosa, existen momentos en donde la inmediatez está presente en la escritura: primero, la rememoración de una jornada que es relatada día con día; segundo, los momentos donde el autor-narrador se dirige a un lector hipotético de forma directa; y tercero, cuando los momentos de reflexión se posicionan en un punto medio entre la intimidad del autor-narrador y el presente cotidiano.

Los hechos cotidianos relatados a partir de una memoria posicionada a corto plazo, dan pie a que haya la mayor inmediatez posible en la narración. Las entradas del diario son una recapitulación de los sucesos de un día, que se centran en el instante de la escritura para crear la sensación en el lector de una construcción de presente inmediato, a partir de diversos elementos. El primero es el desajuste de fechas que realiza el autor-narrador en diversas ocasiones: "El final de la historia quedó para «hoy», o sea el «mañana» de ayer y hoy me siento particularmente nervioso por razones supersticiosas" (Levrero, La novela 244). La cita anterior es un claro ejemplo de una escritura que ocurre en el ahora. Es el instante mismo del presente. Otro de los elementos configurativos del lenguaje es el uso de un tiempo verbal en presente: 
Escribo a la escasa luz del cielo que todavía entra por la ventana y, desde luego, escribo a mano. En estos momentos debería estar en viaje a casa de una amiga, que se fue por unos días y me pidió que le regara las plantas y echara una vista general a su apartamento. Pero el día de hoy traía sus propios designios y en estos momentos he optado por la mansa resignación. (295)

El fragmento anterior inicia con una configuración que posiciona temporalmente al autor-narrador en un presente donde sucede el instante de la escritura. Aquí es donde aparece esa inmediatez del diario, favoreciendo la verdad de los hechos de un diario íntimo que dedica sus líneas a narrar lo cotidiano y lo nimio, a partir de una obsesión en la repetición de imágenes para poder volver un hábito la escritura y así llegar a terminar su proyecto narrativo.

De igual manera, el autor-narrador recurre a otro artificio para crear la sensación de un diálogo constante con el lector. En estos momentos narrativos, se hace referencia a un lector hipotético, pero el humor sórdido del autor-narrador desplaza al lector para que sea menos importante que el texto mismo: "Este recuerdo, que posiblemente ya haya contado en otro lugar, y si es así, que el lector se aguante, porque esto es mi diario y puedo escribir lo que quiera" (135). Estos ataques y menciones del lector funcionan para denotar la resistencia del texto hacia los estatutos literarios, la comercialización de los libros y los concursos monetarios para escritores. De igual manera, la creencia en la existencia de un posible lector da a conocer una sensación de diálogo entre quien escribe y quien lee la información. ¿Quién podría ser aquel lector hipotético? Es claro que podría ser cualquiera, y es aun más probable que sea un Mario Levrero escritor, es decir, podría considerarse un diálogo del mismo autor consigo mismo a partir de la escritura. ${ }^{11}$

${ }^{11}$ El diálogo del autor-narrador con el Mario Levrero autor se da a partir de un soliloquio. De igual manera, la ideología sobre la muerte planteada en el diario íntimo va cambiando al transcurrir el tiempo en el diario, ya que los sucesos que 
Por último, están las reflexiones que aparecen como intergumentos, es decir, argumentos posicionados en un punto medio entre "la realidad cotidiana" narrada y la intimidad del mismo autor-narrador. Estos momentos aparecen como un devaneo de la mente, ya que están colocados a manera de corte repentino:

La tristeza ante la muerte ajena es algo que no entiendo muy bien, o sí, entiendo que es la tristeza por uno mismo y no por el muerto, de quien no hay nada que lamentar — tristeza por lo que a uno le falta, por lo que a uno le faltó decir y hacer, por la culpa real o imaginaria. ... Y el espanto ... porque, mientras mi padre vivía, de un modo mágico era una coraza contra mi propia muerte. El que tendría que vérselas con la muerte era él, y no yo. Y en el mismo momento en que él me faltó, quedé yo enfrentado, mano a mano, con esa buena señora. Sin coraza. (67)

¿Qué es lo que vuelve a este fragmento un intergumento? En los hechos narrados anteriores a lo citado se revela la muerte del Flaco, amigo del autor-narrador. Este suceso genera el recuerdo de la muerte del padre, por lo que pone en su mente los sentimientos de tristeza y espanto ante la muerte. Gracias a la rememoración, que es revelar un estado de intimidad del sujeto, y a la realidad que se vive en el momento, es que se da pie a una reflexión que, al estar narrada en presente, se da en el instante de la escritura misma. Estos intergumentos, que crean un presente al posicionar al lector en el momento de la reflexión, son elementales dentro de la teoría de posautonomía de Josefina Ludmer, ya sea por un diálogo directo con alguien o por el tiempo verbal en el que se configuran.

Recapitulando, las escrituras posautónomas deben ser entendidas como "esas prácticas literarias territoriales de lo cotidiano" (Ludmer, Aqui 150), donde la fabricación de presente y de reali-

ocurren en el día a día relatado generan cambios en la perspectiva del autor-narrador en torno al tema. Esto solo es una hipótesis. 
dadficción son sus dos mayores características. En el caso de la narración de lo nimio dentro de la cotidianidad, se puede encontrar una construcción de un presente constante e inmediato en la sensación del momento de la escritura. Un elemento que Levrero utiliza de forma magistral para la narración de un año de su vida. Por su parte, la realidadficción se construye a partir del uso de la memoria de corto plazo que emplea para las entradas del diario, ya que, pensando desde la perspectiva de Ludmer, la memoria difumina la línea entre realidad y ficción para coexistir en la misma línea de realidad que es el presente.

\section{E1 discurso de los sueños}

Narrar los sueños es dejar al desnudo la intimidad del Inconsciente y los deseos reprimidos u olvidados por el sujeto, o eso es lo que hace el autor-narrador en las entradas del diario íntimo donde los relata. Dentro de los sueños se presentan momentos construidos por el Inconsciente a partir de elementos de la realidad que detallan las experiencias eróticas, simbólicas e, incluso, sobre la muerte. De igual manera, estos sueños son catalogados por el autor-narrador como experiencias parapsicológicas en diversos momentos, es decir, aparecen elementos que se relacionan con sucesos que pasan a futuro a partir de esas conexiones extra sensoriales como precogniciones, telepatía o recursos espirituales.

Cabe destacar la fascinación de Mario Levrero por la parapsicología, una ciencia que, como explica en su Manual de parapsicología, estudia "la fenomenología extraordinaria que tiene su origen en [el] mismo Inconsciente, en las zonas profundas de nuestra mente" (134). La parapsicología, por lo tanto, estudia diversas variantes del Inconsciente, uno de ellos: los sueños. Estos son explicados de la siguiente manera en el Manual:

En el sueño, o en la hipnosis, el yo escapa de los estrechos límites de la conciencia, y sin llegar a ser omnipotente (omnipresente), tiene una amplitud considerablemente mayor. (128) 
De igual manera, para el autor uruguayo, otro escape del yo es la precognición, una "que sorprende a una conciencia limitada, como sorprendería la visión a un ciego. Pero no hay precognición sino expansión del yo, no hay una transgresión del tiempo, porque no hay tiempo. Sólo hay espacio, y un presente que sólo podemos actualizar por medio del tacto" (128). El sentido del tacto, para aclarar su existencia en la cita anterior, es concebido por la parapsicología como creador de presente inmediato, ya que la sensación real dura solo el momento.

Ahora bien, dentro de estos discursos oníricos dados en La novela luminosa, existe un elemento simbólico que gira alrededor de la concepción de la muerte:

En el sueño principal había varias instancias; una de ellas, la que ocupaba más "tiempo" narrativo, se refería a una serie de muertes que tenían un patrón común, como el de los asesinatos. . . hubo una imagen muy clara en la que yo extraía una moneda que mostraba un signo de muerte en una de sus caras. Se trataba de unas monedas adivinatorias, como un tarot de monedas... (Levrero, La novela 213).

En este sueño ocurren dos situaciones, uno es el significado de la muerte en el tarot, donde se plantea que "el significado correcto no [es] la muerte lisa y llana sino esa especie de muerte que es la rutina, el repetir todos los días las mismas cosas" (217). Este significado acerca de la muerte es aplicado en la misma repetición obsesiva dentro de la jornada diaria del autor-narrador, en la que este busca el poder encontrar el retorno a sí mismo.

Ahora bien, para terminar de explicar la experiencia parapsicológica, este sueño mencionado tiene una repercusión más adelante en el texto, ya que el autor-narrador tiene un encuentro con Rubén Kanalenstein en la calle donde vive. Este amigo fue quien le proporcionó el significado de la muerte planteado en el párrafo anterior. Para el autor-narrador, esto es la experiencia a partir de algún elemento parapsicológico, donde "el sueño fue una precognición, un adelantar[se] psíquica mente en el tiempo" (218). Este tipo de conexiones extra sensoriales de la mente, junto con ciertos 
elementos de los sueños, le ayudan a creer en proyecciones a futuro que terminan por suceder en el presente inmediato, ya que, como lo plantea el concepto de precognición, estas proyecciones se perciben solo cuando se viven en el momento.

En el caso de la narración de los sueños, elemento recurrente en el diario íntimo levreriano, se puede observar la configuración de momentos reflexivos en torno a la muerte que se van descubriendo en el proceso de la escritura para el autor-narrador. De igual manera, el uso del sueño como precognición genera una sensación de realidadficción en el lector, ya que el sueño, elemento construido por el Inconsciente, puede considerarse como un elemento ficcional que repercute en un suceso de la realidad dentro de lo narrado.

De ser pensada de esta manera, La novela luminosa, hasta el momento de este análisis, emplea recursos que generan la sensación de realidadficción en el lector como: precogniciones, elementos parapsicológicos y el uso de una retórica de la memoria. De igual manera, aparecen elementos discursivos — narraciones oníricas, retórica testimonial, intergumentos - que configuran momentos reflexivos que indagan sobre aquellas obsesiones del autor-narrador a manera de neoepifanías, en especial, acerca de la muerte.

\section{Más allá de la muerte}

El último discurso que se explicará en este trabajo en torno a $\mathrm{La}$ novela luminosa es el de la observación, discurso que surge a causa del cadáver de una paloma. Debido a esto, el autor-narrador comienza a construir una historia en torno a una familia de palomas y comienza a deducir los hechos que suceden después de la muerte de un individuo.

El percibir la existencia del cadáver y la llegada de una paloma que llama — la viuda - son los elementos que lo intrigan para seguir observando durante meses a una paloma muerta por esa ventana que da a la azotea vecina. Gracias a esto comienza una construcción imaginaria, hasta cierto punto, donde la realidadficción está presente: 
Yo me había subido a la bicicleta fija, y había empezado a pedalear lentamente, como para aprovechar el tiempo mientras esperaba ver qué hacía la viuda. . . Parecía una escena familiar, la forma de instalarse la viuda creaba un ambiente amable y tierno, conmovedor; un ambiente de hogar, de nido. Sólo faltó que se pusiera a tejer. (194)

El fragmento anterior es un claro ejemplo del uso de la imaginación sobre la realidad. La paloma viuda, quien está cerca del cadáver de su posible marido, rehace su vida con otra paloma macho y llega a tener hijos. El uso de la prosopopeya es de suma importancia en este caso, ya que, al utilizar esta figura retórica, se logra un acto de ficcionalización de la realidad. La imaginación logra fusionarse con la realidad para generar un instante reflexivo.

De igual manera, la paloma tiene un carácter simbólico para el autor-narrador, el cual aparece en la forma de un pichón en Diario de un canalla. El significado está en la siguiente mención del autor-narrador: "Un símbolo de mi espíritu muerto que ninguna viuda (digamos, mi yo consciente) podrá resucitar a pesar de todos sus esfuerzos" (200). Aquí inicia la caída del proyecto de la beca, la paloma está muerta, por lo tanto, la posibilidad de escritura también: "Esto es triste, pero es coherente. ¿Por qué estar atento solamente a los símbolos alentadores? Me preocupa mucho la idea de que mi espíritu esté muerto -al menos, el espíritu que me llevó a escribir la novela luminosa" (200).

Por su parte, las reflexiones que aparecen en torno a la muerte en La novela luminosa llegan a volverse una neoepifanía, pensada desde la perspectiva de Óscar Brando. En la novela no existe una explicación como tal, pero los fragmentos esparcidos a manera de destellos a lo largo del texto, logran construir una imagen de lo que para el autor-narrador es la muerte. Ahora bien, ¿cómo es que la neoepifanía se construye? La configuración de una luminosidad que exorcice un temor a la muerte se da a partir de ciertos momentos reflexivos que ocurren en una inmediatez. La revelación en este caso no es pretextual, como ocurre con la epifanía, sino que se da a partir de una sensación de presente inmediato en el acto de escribir 
gracias al tiempo verbal en el que se narran los momentos, las alusiones al lector que generan un diálogo hipotético y los devaneos que cortan el mismo hilo narrativo para profundizar en el tema. En pocas palabras la neoepifanía sobre la muerte aparece durante el proceso de escritura.

Por último, la neoepifanía construida termina por hacer ver que la muerte de un individuo es la causa de sentimientos de tristeza y espanto, de que la vida para los vivos sigue y debe reconstruirse, no sin extrañar al difunto; al igual que, al saber de la existencia de la muerte de algún ser querido, los recuerdos de buenos y malos momentos deben ser rememorados para generar nostalgia hacia lo perdido. Pero esta muerte no debe ser tomada como algo físico solamente, porque también puede ser tomada como la muerte de la paloma en la azotea vecina, es decir, como la muerte simbólica del espíritu que impulsó el proyecto de la búsqueda de una luminosidad.

\section{Conclusiones: nuevas perspectivas de lectura-escrituras críticas}

La narrativa testimonial tuvo su auge en la década de 1990 y puede considerarse como una constante en América Latina, donde escritores logran generar una configuración de elementos que cruzan las fronteras entre las relaciones binarias y al mismo tiempo generan la construcción de una temporalidad y territorialidad del presente. En el caso de La novela luminosa de Mario Levrero, como se explicó a lo largo de este artículo, la construcción de un presente se da a partir de la sensación del instante de la escritura en las entradas del diario íntimo y, de igual manera, se va construyendo una neoepifanía en torno al tema de la muerte del individuo y de la muerte simbólica del espíritu que impulsa a la búsqueda de una luminosidad. Esto se da a partir de los tres discursos mencionados antes: el de la vida cotidiana, el de los sueños y el de la observación.

Por su parte, la novela del autor uruguayo logra posicionarse en una concepción contemporánea que la hace criticar al estatuto literario de lo autónomo a partir de elementos que van desde su 
propia estructura, es decir, existe un prefacio, un prólogo, la novela y un epílogo; todos escritos por Levrero para generar un juego autorial donde aparece un autor-narrador. A su vez, está el uso de un tiempo verbal del presente que, combinado con los momentos reflexivos donde el devaneo se convierte en un corte momentáneo de la linealidad, logra crear esa sensación de instante en el lector. Por último, la existencia de los sueños como precogniciones de un futuro, al igual que el uso de la imaginación para crear historias a partir de la observación, ayudan a la configuración de una realidadficción como la plantea Josefina Ludmer, ya que la ficción se vuelve parte de la realidad borrando la limitación de fronteras entre la relación binaria.

Durante este análisis se planteó una nueva perspectiva de lectura que logra posicionarse más allá de la concepción de autonomía de la literatura, ya que La novela luminosa puede ser leída desde esos preceptos, pero posicionarla desde la posautonomía es llevarla por otro rumbo. Este trabajo escudriña en la complejidad de una configuración narrativa e ideológica por parte de Mario Levrero, para poder posicionarlo en los términos contemporáneos que han aparecido, en las ideologías y concepciones dadas durante la posmodernidad. De igual manera, la novela de Levrero debe ser entendida no solo desde un nuevo modo de leer, sino que, debe posicionarse como una novela que critica lo autónomo, los concursos literarios, la idea acerca de qué es una novela como género literario y la comercialización del libro como objeto.

Por último, este trabajo propone una nueva línea de investigación en torno a la Trilogía luminosa de Mario Levrero, al igual que de otro tipo de escrituras que construyan territorialidades y temporalidades del presente, para poder ubicarlas dentro de los nuevos modos de lectura y criticarlas desde una concepción literaria que va más allá de la autónoma, una en la que existe una concepción temporal donde el recordar el pasado se vuelve presente y la promesa por un futuro se ha perdido. 


\section{Bibliografía}

Adorno, Theodor. "Reconciliation under duress". Aesthetics and politics. Verso, 2007, pp. 151-76.

Arce, Rafael. "La genealogía del monstruo". Los límites de la literatura, editado por en Alverto Giordano. Universidad Nacional del Rosario / Centro de Estudios de Literatura Argentina, 2010, pp. 17-32.

Benjamin, Walter. "Tesis de la filosofía de la historia". Angelus novus, Comares, 2012, pp. 37-46.

Brando, Óscar. "Huir hacia adelante: cómo salir de las literaturas posautónomas". Revista de la Biblioteca Nacional. Época 3, año 4, no. 6-7, 2012, pp. 239-48.

Contreras, Sandra. "Cuestiones de valor, énfasis del debate". Boletín 15, dossier: Cuestiones de valor, Facultad de Humanidades y Artes / Centro de Estudios de Teoría y Crítica Literaria, Universidad Nacional de Rosario, octubre de 2010, pp. 1-10.

Corbellini, Helena. "La trilogía luminosa de Mario Levrero". Revista de la Biblioteca Nacional. Época 3, año 3, no. 4-5, pp. 251-62.

Giordano, Alberto. "Tal vez un movimiento. Sobre En pausa, de Diego Meret". Revista de la Biblioteca Nacional. Época 3, año 3, no. 4-5, pp. 241-49.

Laddaga, Reinaldo. "Un autor visita su casa. Sobre La novela luminosa, de Mario Levrero". La máquina de pensar en Mario. Ensayos sobre la obra de Levrero. Eterna Cadencia, 2013, pp. 223-36.

Levrero, Mario. La novela luminosa. De Bolsillo, 2008.

" "Tratado especulativo de parapsicología", "Parapsicología: una ciencia frente a los prejuicios". Manual de parapsicología. Criatura Editora, 2019, pp. 127-29, 131-38.

Ludmer, Josefina. Aqui en América Latina. Una especulación. Eterna Cadencia, 2010.

. “Cómo salir de Borges?”. Jorge Luis Borges. Intervenciones sobre pensamiento y literatura, editado por en William Rowe, et al., Paidós, 2000, pp. 289-300.

Sarlo, Beatriz. "Crítica del testimonio: sujeto y experiencia", "La retórica del testimonio". Tiempo pasado: cultura de la memoria y giro subjetivo. Una discusión, Siglo XXI, 2006, pp. 27-58, 59-94. 
58 Del diario a la ePifanía: UNA LeCtura posautónoma de La nOVELA LUMINOSA...

. “Pornografía o fashion?”. Revista Punto de Vista. Año XXVIII, no. 83 , pp. 13-27.

Schaff, Adam. "La relación cognoscitiva. El proceso de conocimiento. La verdad”. Historia y verdad. Grijalba, 1982. 